\title{
A rare case of Wilms Tumor in the right atrium.
}

1. FCPS (Pediatric Medicine) Fellow Pediatric Cardiology NICVD, Karachi.

2. FCPS (Pediatric Medicine) Fellow Pediatric Cardiology NICVD, Karachi.

3. FCPS (Pediatric Medicine) Assistant Professor Pediatrics Ghurki Trust Teaching Hospital, Lahore.

4. FCPS (Pediatric Medicine) Assistant Professor Pediatric Medicine

Chandka Medical College, Shaheed Mohtarma Benazir Bhutto Medical University, Larkana.

5. FCPS (Pediatric Medicine) Consultant Pediatrician Medicine Govt. Shahbaz Sharif DHQ Hospital, Multan.

6. MBBS

Clinical Fellow Pediatric Cardiology NICVD, Karachi.

\section{Correspondence Address:}

Dr. Fazal ur Rehman

Department of Pediatric Cardiology

NICVD, Karachi.

fazal171@gmail.com

Article received on: 10/02/2021

Accepted for publication:

22/04/2021

\begin{abstract}
Fazal ur Rehman', Shakeel Ahmed², Waqas Ali ${ }^{3}$, Asif Ali Khuhro ${ }^{4}$, Sabiha Khan ${ }^{5}$, Basharat Hussain ${ }^{6}$
ABSTRACT... Improvement in outcome of Malignant solid tumor cases is credited to existence of well-defined guidelines and protocols and integrated treatment modalities involving chemotherapy, surgery and radiotherapy. The present case describes a rare case of Wilms tumor extending from the left kidney to left renal vein and then via inferior vena cava into the right atrium. This patients was 5 years of age and resident of Karachi presented to the outdoor of National Institute of Child Health $(\mathrm{NICH})$ with the complaints of progressively increasing abdominal distension over the last two months that exacerbated with the agony of swelling in both lower limbs. On physical examination, a mass was palpable in the left abdominal area not crossing the midline. On initial scrutiny with haematological testing and the basic radiology workup in the form of ultrasound abdomen, the patient was found to have a mass originating in the left kidney and invading the left renal vein. CT scan abdomen with contrast revealed that the patient had a heterogeneously enhancing mass of $12 \times 9 \mathrm{~cm}$ originating from the left kidney and invading the left renal vein. The size of the tumor encroaching into the right atrium cavity was $19.5 \times 20.5 \mathrm{~mm}$.
\end{abstract}

Key words: $\quad$ Atrium, Solid Malignant Tumor, Wilms Tumor.

Article Citation: Fazal ur Rehman, Ahmed S, Ali W, Khuhro AA, Khan S, Hussain B. A rare case of Wilms Tumor in the right atrium. Professional Med J 2021; 28(6):928-930. https://doi.org/10.29309/TPMJ/2021.28.06.6415

\section{INTRODUCTION}

Malignant solid tumors are the cause of significant amount of morbidity and mortality in pediatric age groups. ${ }^{1}$ Malignant solid tumors form around $50 \%$ of all pediatric malignancies. ${ }^{2}$ Wilms Tumor is known to be the $5^{\text {th }}$ commonest pediatric malignancy and accounts for nearly 650 children every year in the United States. ${ }^{3-5}$

Over the past few decades, data from developed countries revealed dramatic improvement in outcome of solid tumors among children. ${ }^{6,7}$ Improvement in outcome of these cases is credited to existence of well-defined guidelines and protocols and integrated treatment modalities involving chemotherapy, surgery and radiotherapy. ${ }^{8}$

Although, most frequently found tumors among children are described as Wilms tumors, neuroblastoma, Iymphoma, retinoblastoma and bone tumors and all of these usually occur in children below 5 years of age..$^{9}$ In Pakistan, no national data exists regarding Wilms tumor but research done by "Pakistan Medical Research Council Cancer Study Group" showed malignant tumors to form $4.4 \%$ of total malignancies identified in children below 15 years of age..$^{10}$ The present case describes a rare case of Wilms tumor extending from the left kidney to left renal vein and then via inferior vena cava into the right atrium.

\section{Case Presentation}

This patient was 5 years of age and resident of Karachi presented to the outdoor of National Institute of Child Health $(\mathrm{NICH})$ with the complaints of progressively increasing abdominal distension over the last two months that exacerbated with the agony of swelling in both lower limbs. The patient was admitted.

On physical examination, a mass was palpable in the left abdominal area not crossing the 
midline. On initial scrutiny with haematological testing and the basic radiology workup in the form of ultrasound abdomen, the patient was found to have a mass originating in the left kidney and invading the left renal vein. Serum albumin, renal function tests, liver function tests and the complete blood profile were almost within normal physiological limits. To extend the basic investigation scheme, the patient was then advised CT scan abdomen with contrast. The report of the CT scan said that the patient had a heterogeneously enhancing mass of $12 \times 9$ $\mathrm{cm}$ originating from the left kidney and invading the left renal vein. The oncology department of $\mathrm{NICH}$ was then involved for needle biopsy of the lesion to narrow down the list of differentials of abdominal masses and initiate the definite treatment as per the conclusive diagnosis. In the meanwhile, the patient was discharged from the $\mathrm{NICH}$ and referred to the National Institute of Cardiovascular Diseases for delineating the anatomy/extent of the mass involvement of the inferior vena cava, as it was commented in the CT abdomen contrast, and to find out if the mass was vigorous enough to spread to the heart.

The images in Figure-1 show minimal blood flow into the inferior vena cava due to intravenous extension of the tumor. The size of the tumor encroaching into the right atrium cavity was $19.5 \times 20.5 \mathrm{~mm}$. As the report of the biopsy was followed from the Oncology Department, it was later confirmed that the mass in the right atrium is actually Wilm's tumor extending from the left kidney to left renal vein and then via inferior vena cava into the right atrium.

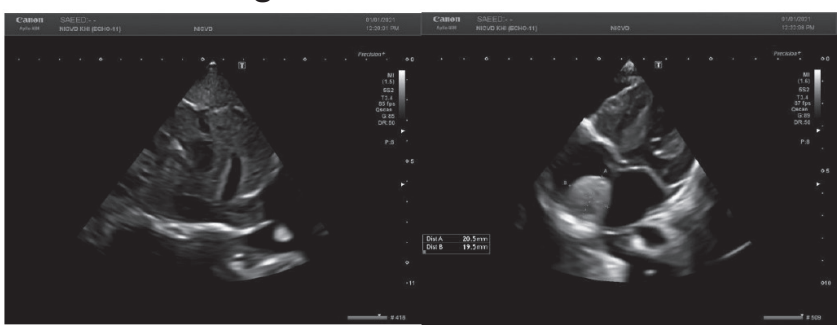

Figure-1. Transthoracic echocardiography.

\section{DISCUSSION}

Exact causes of Wilm's Tumor are not known but genetic alterations dealing normal embryological development of the genitourinary tract are thought to be major cause. Few of the known genetic markers linked with Wilms tumor are WT1, CTNNB1 as well as WTX gene alterations which are identified in about $1 / 3^{\text {rd }}$ of all Wilms Tumor cases. ${ }^{12,13}$ Generally, a poor prognosis is associated with TP53. Around 1\% cases of Wilms tumor have someone in their relative (other than parents) with this disease. ${ }^{13}$

Wilms is considered to form from persistent metanephric tissue or nephrogenic rests. These anomalous metanephric cells are identified in about all cases of bilateral Wilms tumors but in around $35 \%$ cases of unilateral tumors. ${ }^{13}$ In children, majority of Wilms tumor present as asymptomatic abdominal mass while other commonly found features include abdominal pain, gross hematuria, urinary tract infection, varicocele, hypertension or hypotension, fever or anemia. Abdominal pain is noted to be the most frequently occurring early presenting symptom noted in $30-40 \%$ of children. ${ }^{13}$ Present case presented to us with complaints of progressively increasing abdominal distension over the last two months that exacerbated with the agony of swelling in both lower limbs.

Past researchers have found no major distinction in usually asked laboratory investigations but those need to be asked to rule out any other concomitant pathological conditions. ${ }^{14,15}$ In our patient, serum albumin, renal function tests, liver function tests and the complete blood profile were ordered and found to be almost within normal limits.

\section{Copyright@ 22 Apr, 2021.}

\section{REFERENCES}

1. Barr R, Riberio R, Agarwal B, Masera G, Hesseling $\mathrm{P}$, Magrath I. Pediatric oncology in countries with limited resources. In: Pizzo PA, Poplack DG, editors. Principles and practice of pediatric oncology. 5th ed. Philadelphia: Lippincott Williams and Wilkins; 2006. pp. 1605-17.

2. Altman AJ, Schwartz AD. Diagnosis of cancer in childhood. In: Altman, A.J. and Schwartz, A.D. eds. malignant diseases of infancy, Childhood and adolescence, 2nd Ed. Philadelphia: WB Saunders Co, 1983; pp 3-10. 
3. Caldwell BT, Wilcox DT, Cost NG. Current management for pediatric urologic oncology. Adv Pediatr. 2017; 64(1):191-223.

4. Szychot E, Apps J, Pritchard-Jones K. Wilms' tumor: Biology, diagnosis and treatment. Transl Pediatr. 2014; 3(1):12-24.

5. Farooq $U$, Qazi AQ, Malik AA. Short term surgical outcomes of Wilms tumour from a single institute. $J$ Pak Med Assoc. 2018; 68(7):1129-31.

6. Fuchs J. Surgical concepts in the treatment of Wilms tumour: An update. Urologe A. 2015; 54:1784-91.

7. Godzinski J, Graf N, Audry G. Current concepts in surgery for Wilms tumour-the risk and functionadapted strategy. Eur J Pediatr Surg. 2014; 24: 457-60.

8. Safdar CA, Aslam M, Awan SH, Ahmed I, Badshah S. Wilms' tumour: A comparison of surgical aspects in patients with or without pre-operative chemotherapy. J Coll Physicians Surg Pak. 2006; 16(8):521-4.

9. Shamas-uz-Zaman SMA. Incidence of pediatric malignancies in the INMOL series of cancer patients. Pak Pediatr J. 1990; 14:10-6.
10. Jafarey NA. Frequency of malignant tumors in seven centers of Pakistan. Pakistan Medical Research Council Cancer Study Group. J Pak Med Assoc. 1977:27:335-9.

11. Oh L, Hafsi $H$, Hainaut $P$, Ariffin $H$. p53, stem cell biology and childhood blastomas. Curr Opin Oncol. 2019; 31(2):84-91.

12. Kitagawa K, Gonoi R, Tatsumi M, Kadowaki M, Katayama T, Hashii Y, Fujisawa M, Shirakawa T. Preclinical development of a WT1 oral cancer vaccine using a bacterial vector to treat castration-resistant prostate cancer. Mol Cancer Ther. 2019; 18(5):980-990.

13. Leslie SW, Sajjad H, Murphy PB. Wilms tumor. [Updated 2020 Nov 20]. In: StatPearls [Internet]. Treasure Island (FL): StatPearls Publishing; 2020.

14. de la Monneraye $\mathrm{Y}$, Michon J, Pacquement $\mathrm{H}$, Aerts I, Orbach D, Doz F, et al. Indications and results of diagnostic biopsy in pediatric renal tumors: A retrospective analysis of 317 patients with critical review of SIOP guidelines. Pediatr Blood Cancer. 2019 Jun; 66(6):e27641.

15. Biderman WM, Lindhurst M, Keppler-Noreuil KM, Sapp JC, Baker L, Gripp KW, et al. Urine cell-free DNA is a biomarker for nephroblastomatosis or Wilms tumor in PIK3CA-related overgrowth spectrum (PROS). Genet Med. 2018; 20(9):1077-1081.

\begin{tabular}{|c|l|l|l|}
\hline \multicolumn{3}{|c|}{ AUTHORSHIP AND CONTRIBUTION DECLARATION } \\
\hline Sr. \# & \multicolumn{1}{|c|}{ Author(s) Full Name } & \multicolumn{1}{|c|}{ Contribution to the paper } & Author(s) Signature \\
\hline 1 & Fazal ur Rehman & Data collection, Final approval. \\
2 & Shakeel Ahmed & Data collection, Proof reading. \\
\hline 3 & Waqas Ali & Literature review. \\
4 & Asif Ali Khuhro & Drafting, Discussion. \\
\hline 5 & Sabiha Khan & Literature Review. \\
6 & Basharat Hussain & Data collection, References. \\
\hline
\end{tabular}

